\title{
Estado, nacionalismo y exclusión ciudadana: apuntes históricos desde el caso boliviano
}

\author{
David Gomes \\ Universidad Complutense de Madrid \\ Instituto Universitario de Investigación Ortega y Gasset \\ Fundação para a Ciência e a Tecnologia de Portugal \\ davidmrgomes@hotmail.com.
}

Fecha de recepción: 04/03/2012

Fecha de aceptación: 25/09/2012

\begin{abstract}
RESUMEN
Las insuficiencias de la construcción nacional en Bolivia han sido tradicionalmente explicadas a través del fracaso del proyecto integrador del republicanismo decimonónico. El presente artículo sostiene que, por el contrario, la consolidación de la nación liberal y la adopción de una ciudadanía extendida a toda la población habrían perjudicado a los intereses de las élites políticas y económicas criollas. El deseo de conservación de su poder de clase, heredado de las jerarquías coloniales orientó, primero, la prolongación del pacto colonial con las poblaciones indígenas y, luego, el cambio en el modelo económico, la privatización de las tierras comunales y la racialización de la cuestión indígena. Las comunidades del Altiplano, dotadas de un débil sentimiento de pertenencia nacional, reaccionaron ante los ataques a su autonomía oscilando entre el sometimiento, la negociación y la violencia, aprovechando los conflictos entre facciones de la élite criolla para asumirse como un actor influyente en la vida política boliviana.
\end{abstract}

Palabras clave: Nacionalismo, Ciudadanía, Élites criollas, Participación indígena.

\section{State, Nationalism, and Civic Exclusion: Historical Notes from the Bolivian Case}

\begin{abstract}
The shortcomings of nation-building in Bolivia have traditionally been explained as the failure of the integration project designed by nineteenth-century republicanism. This article argues that, on the contrary, liberal consolidation of the nation and the adoption of expanded citizenship would have harmed the interests of Creole political and economic elites. The conservation of its class power inherited from the colonial hierarchy oriented, at first, the extension of the colonial pact with indigenous people and, later on, the change of the economic model, the privatization of communal lands and the racialization of the indigenous issue. Altiplano communities, caracterized by a weak sense of national belonging, reacted to these attacks on their autonomy with tactics of submission, negotiation and violence, while taking advantage of conflicts between factions of the Creole elite to become an influential player in Bolivian political life.
\end{abstract}

Key words: Nationalism, Citizenship, Creole Elites, Indigenous Participation. 
La ciudadanía plena para la totalidad de los habitantes de los países andinos había sido, desde antes de la independencia, un espejismo inspirado por buenas intenciones pero lastrado por su aprovechamiento por parte de las estructuras del poder colonial. Aunque finalmente propuesto por Bolívar y la ideología traída por los ejércitos libertadores colombianos, el constitucionalismo liberal había vivido su primera experiencia en Bolivia de 1812 a 1814, bajo autoridad todavía metropolitana, en el marco de las Cortes de Cádiz. Este bautismo del sufragio universal (masculino) fue relativamente respetado en el Alto Perú: el derecho a elegir y ser elegido para las instancias municipales se extendió a todos los hombres, salvo los "conciertos" o indígenas siervos de las haciendas.

En la práctica, sin embargo, este proceso electoral "gaditano" quedó marcado por dos características que se repetirían en el resto de la historia republicana boliviana. Por un lado, en los pueblos mixtos en que los habitantes pudieron expresarse con relativa libertad, los regidores elegidos eran mitad indígenas, mitad criollos: confirmándose así la estructura dual de castas. Por otro, en las localidades donde el poder represivo y la propiedad agraria ya estaban concentrados en las manos de una familia o clan, la fuerza de trabajo indígena con derecho de voto se convirtió fácilmente en electorado cautivo.

Ambos casos sugieren que las estructuras tradicionales de organización social asomaban por debajo de los intentos de innovación política y pervertían los esfuerzos de ampliación del estatuto de ciudadanía. Las contradicciones entre los mensajes igualitarios de los generales y políticos liberales y el inmovilismo socioeconómico del campo boliviano llevaron a las autoridades estatales a pronunciarse por la preservación del segundo, lo que acarreó la restricción drástica del acceso a los derechos políticos, el regreso del tributo indígena y el freno al desmembramiento de las tierras comunitarias indígenas. Fue, a fin de cuentas, la confirmación de que el sueño de Bolívar era importado: lo que podría valer para Norteamérica o Europa - o incluso para la Gran Colombia - no podía ser transpuesto tal cual a las sociedades andinas.

Casi un siglo después, la situación permanecía estancada en una ciudadanía numéricamente exigua. Según el censo de 1900, Bolivia contaba con aproximadamente un millón y seiscientos mil habitantes. El 90\% eran considerados indígenas por las autoridades ${ }^{1}$, siendo la gran mayoría analfabeta. Doce años antes, en las elecciones de 1888, el número de electores no iba más allá de 32.110 , o sea, menos de $2,5 \%$ de la población total. Teóricamente, la condición de elector era atribuida según criterios pecuniarios, pero al final eran la instrucción y la presión de los potentados locales lo que determinaba quién podía votar o no. Del total de inscritos, muchos no llegaban a votar. Y una buena parte de ellos elegía su candidato de acuerdo a amistades y a obediencias jerárquicas. En su estudio fundador sobre la construcción nacional en Bolivia, Marie-Danielle Demélas estima la clase política dirigente en la misma época en alrededor de quinientos hombres, divididos en sectores a menudo en conflicto pero al fin y al cabo con intereses semejantes ${ }^{2}$.

\footnotetext{
1 República de Bolivia: Censo General de la Población de la República de Bolivia según el empadronamiento de 1900, La Paz, Gobierno de José Manuel Pando, 1900.

2 Demélas, Marie-Danielle: Nationalisme sans nation? La Bolivie au XIXe-XXe siècles, Paris, CNRS, 1980, p. 123
} 
Complicidad entre sectores de las élites, privatización del poder represivo y del voto, continuidad de prácticas coloniales, exclusión ciudadana: la emancipación de la Corona española, si bien se plasmó en la independencia de los Estados americanos, no garantizó ni su integración territorial ni una igualdad entre sus habitantes. «Su precoz nacimiento [el de las naciones latinoamericanas] revela, con una particular acuidad, la distancia que separa la nación como comunidad política soberana de la nación como comunidad de individuos-ciudadanos, y de la nación como identidad colectiva, con un imaginario común compartido por todos sus habitantes» ${ }^{3}$. En Bolivia, esta distancia era particularmente grande. El republicanismo liberal, al imponer una igualdad entre todos los ciudadanos negando la diversidad inherente a la sociedad estamental del Antiguo Régimen (que el absolutismo borbónico también había querido quebrantar), abrió paso a una instrumentalización del modelo del Estado y del constitucionalismo modernos por los poderes fácticos tradicionales. Si volvemos a la situación un siglo después de la emancipación, la "armonía de desigualdades" evocada por el Presidente boliviano Bautista Saavedra corrobora la perennidad de las estructuras del Antiguo Régimen y de la mentalidad colonial bajo la envoltura del igualitarismo liberal ${ }^{4}$. La poca difusión del término "ciudadano" más allá de los documentos administrativos, a la par de la longevidad de los calificativos raciales, ilustra la liviandad del Estado-nación boliviano casi un siglo después de su fundación.

Las distintas historiografías nacionales han considerado tradicionalmente el proceso de construcción nacional en América Latina como un fenómeno gradual y evolutivo. La integración de "lo indio" a la modernidad - pues de eso se trataba en gran medida - se habría intentado desde un primer momento: ¿o no es cierto que la Constitución española de 1812 ofrecía el ámbito municipal como vía de incorporación indígena a la ciudadanía? Por otro lado, si el constitucionalismo gaditano venía a romper por primera vez el pacto informal de autonomía que la Corona española había concedido a las poblaciones indígenas, su objetivo era presuntamente meritorio: equiparar a criollos, mestizos e indios, todos propietarios, todos votantes, todos ciudadanos. La ciudadanía en común existía, ahora había que perfeccionarla ${ }^{5}$.

Como apunta Bartolomé Clavero, la historiografía criolla latinoamericana estableció -idea que sigue presente en el constitucionalismo actual- como punto de partida de los nuevos países este concepto de ciudadanía en común que se asume como la principal herramienta para superar las diferencias sociales y culturales y lograr la integración nacional: «Incluso los mecanismos de exclusión que (...) afectan masivamente a los indígenas, como el requisito de una alfabetización que se sobreentiende

3 Guerra, François-Xavier: "Introducción”, en Annino, A. y Guerra, F.-X. (coords.), Inventando la Nación. Iberoamérica. Siglo XIX, México, Fondo de Cultura Económica, 2003, p. 9.

4 «El error sustancial de la democracia, tal como ha venido entendiéndose, ha estado en haber proclamado como principio suyo la igualdad. En apoyo a este principio se invocó la naturaleza; pero la naturaleza, que es una hermosa armonía de desigualdades, no ha hecho otra cosa que desmentir constantemente esta ilusión, porque, un régimen de libertad, no puede ser sino ambiente de florecimientos de desigualdades». Esta crítica involuntaria de la ceguera del constitucionalismo liberal da título a un libro de Marta Irurozqui sobre las élites paceñas a la vuelta del siglo XIX y XX, del que se toma la cita: IRUROzQUi, Marta: La armonía de las desigualdades: elites y conflictos de poder en Bolivia: 1880-1920, Cusco, CSIC-CBC, 1994, p. 7.

5 Clavero, Bartolomé: Geografía jurídica de América Latina: pueblos indigenas entre constituciones mestizas, México, Siglo XXI, 2008, pp. 45-47. 
siempre en castellano, llegan a aparecer en dicha narrativa como condición lógica y acicate eficaz para la consecución del objetivo de la comunidad de ciudadanía $\rangle^{6}$. La comunidad de iguales se alcanzaría a largo plazo por la práctica reiterada de la desigualdad constitucionalmente sancionada. Si el nacionalismo es «la batalla por la definición de la verdad, por el poder de determinar las verdades y mentiras dominantes $»^{7}$, el constitucionalismo republicano y el mito de la ciudadanía en común proporcionaban a los sectores criollos no sólo todos los triunfos sino también la posibilidad de elegir el naipe del juego político nacionalista.

De acuerdo con la evolución arquetípica de la construcción nacional, el Estadonación, al fomentar una etnicidad abstracta o ficticia, tiende a eliminar formas prenacionales de solidaridad fundadas sobre parentesco, linaje o clientelas. En esos territorios, el nacionalismo se asume como la fuerza motriz de un proceso por etapas que, basado en una comunidad abstracta de ciudadanos legales, le confiere un sentimiento de pertenencia común, una identidad distintiva y un proyecto de futuro llamados a desembocar en la conformación de la nación. Este es, a grandes rasgos, el modelo evolucionista de Estado-nación que se suele aplicar a la historia de los Estados latinoamericanos, entidades nacidas de la desintegración del Imperio español más que de la perseverancia de sus movimientos nacionalistas.

En Bolivia, sin embargo, la relación entre Estado y nacionalismo - entendido aquí como proceso de formación de la nación - no parece tan lineal ni ineludible. Recordemos la fórmula de Ernest Renan, en su texto clásico ¿Qué es una nación?: «La esencia de una nación consiste en que todos los individuos tengan muchas cosas en común, y también en que todos hayan olvidado muchas cosas» ${ }^{8}$. Pero, ¿qué pasa cuando lo que el nacionalismo de Estado decide olvidar es a la mayoría de la población? ¿Puede la nación consolidarse a espaldas del 90\% de sus habitantes? Es más: ¿el discurso nacionalista de las élites criollas buscaba in fine la integración ciudadana bajo una u otra forma, o asentar las bases de la reproducción de su posición dominante sobre la economía y el aparato estatal manteniendo los sectores subalternos al margen del proceso político? Compartiendo los argumentos iniciales de Marta Irurozqui, y refutando un teleologismo nacionalista eurocéntrico, partimos del principio de que la construcción nacional no era un objetivo prioritario, ni tampoco útil, para los intereses de las élites dirigentes bolivianas y de los grupos de poder que representaban ${ }^{9}$. Su propósito de conservación del poder manteniendo los grupos subalternos a distancia - frenando tanto la ascensión social como la rebelión a gran escala - ya había, como hemos visto, quedado grabado en el momento fundador de las repúblicas andinas. Desde esta perspectiva, la relación entre Estado-nación moderno, nacionalismo e inclusión ciudadana deja de ser cooperativa y pasa a ser de potencial incompatibilidad.

\footnotetext{
6 Ibidem, pp. 47-48.

7 Miller, Christopher: Nationalists and Nomads. Essays on Francophone African Literature and Culture, Chicago, University of Chicago Press, 1998, p. 124.

8 Renan, Ernest: “¿Qué es una nación?” [en línea], conferencia dictada en la Sorbona, París, 11 de marzo de 1882, p.4 www.paginasprodigy.com/savarino/renan.pdf [Consulta: 30 de abril de 2012]

9 IRUROZQUi, op.cit. (nota 4), p. 16.
} 


\title{
Nacionalismo en el contexto del siglo XIX boliviano
}

\begin{abstract}
¿Podemos hablar de nación cuando la mayor parte de las contradicciones entre clases o capas sociales se resuelven sistemáticamente con el recurso a la violencia armada? ¿Cuando una fracción de la población, la minoría blanca, afirma ahincadamente no tener ningún punto en común, ninguna relación con la mayoría india cuyos miembros no gozan del estatuto de ciudadanos? ¿Cuando aquellos que hablan con más énfasis de nacionalismo reducen la nación a algunos millares de individuos? ${ }^{10}$
\end{abstract}

Replantear la relación entre proyecto nacionalista, construcción nacional e integración ciudadana bajo el prisma de las relaciones de poder intra e inter clases nos conduce paradójicamente a afirmar que el nacionalismo decimonónico de las élites políticas criollas no fracasó: para fracasar en algo hay que intentarlo, e intentarlo con convicción. El proyecto nacionalista nunca tuvo como objetivo la democracia, la integración nacional o la igualdad de derechos: en efecto, «la élite boliviana se veía envuelta en un proyecto anterior al nacional: tenía que resolver ante todo su propia continuidad» ${ }^{11}$. Y, en ese proyecto, acabó siendo relativamente exitosa.

Es cierto que las propias condiciones naturales, demográficas e históricas del territorio tampoco favorecían una homogeneización de la población, fuese esta étnica o cultural, y una integración territorial. Bolivia tenía una reducida densidad de población aliada a espacios fragmentados y de difícil acceso. Mientras Argentina y Uruguay exterminaban a los grupos autóctonos y homogeneizaban su población, Bolivia dependía financieramente y laboralmente de su mayoría indígena y no tenía sentido suprimir la principal fuente de ingresos del Estado. Por otro lado, la inestabilidad política que rigió durante la mayor parte de la centuria tampoco favoreció el advenimiento de una política estatal de irradiación nacionalista; la precipitada sucesión de cartas magnas durante las décadas caudillistas frenó la difusión de un mito constitucionalista fundacional al que la sociedad pudiera atar sus amarras afectivas y legales, como en Estados Unidos.

¿Pero son estos los únicos factores que explican que las recetas de la modernidad para "nacionalizar" el Estado no se hayan impuesto en el siglo XIX boliviano? A pesar de las circunstancias adversas descritas arriba, lo más destacado es que las élites dirigentes nunca parecieron empeñadas en diseñar y llevar a buen puerto esa política, y la construcción del Estado-nación fue efectivamente relegada a un segundo plano. Así se entiende que el centralismo lingüístico-cultural implementado por los países europeos a partir del siglo XVIII no fuese adoptado por la recién creada Bolivia: además de la falta de medios, enseñar español implicaba dar argumentos a favor de la integración política de los pueblos indígenas. De igual modo, la creciente eficacia burocrática de los Estados occidentales centralizados y la consecuente ampliación de la presencia del Estado tampoco tuvo lugar en el territorio boliviano hasta bien entrado el siglo $\mathrm{XX}^{12}$. Mientras tanto, el gamonalismo controlaba vastas zonas del

10 DemÉLAs, op.cit. (nota 2), p. 95.

11 IrURozQui, op. cit (nota 4), p. 18.

12 Demélas, op. cit. (nota 2), p. 65, recuerda que, en 1879, el Estado contaba con tan sólo 816 funcionarios a su sueldo. A estos habría que añadir aquellos que sacaban ingresos directamente de su función, como los corregidores o los jueces de paz. Aún así, un número más que insuficiente. 
agro boliviano y mantenía estrechos vínculos clientelares con las élites políticas y económicas urbanas ${ }^{13}$.

La conciencia de la posible inadecuación entre conservación del poder y otorgamiento generalizado de la ciudadanía fue rápidamente desarrollada por los sectores dirigentes. Como sugiere Gonzalo Rojas Ortuste en su reciente estudio sobre la cultura política de las élites bolivianas, el ideal republicano inicial de soberanía popular propio del Estado-nación burgués coexistió con (y fue prácticamente anulado por, añadiríamos) la preponderancia de la autoridad militar sobre el sector político, resultante del largo conflicto por la independencia, y la persistencia de jerarquías étnicas y clasistas imprescindibles para la manutención del orden social de matriz colonial ${ }^{14}$. El contraste entre la adhesión entusiasta de los Andes - indios y criollos - a los postulados políticos de las Cortes de Cádiz y el retroceso de los preceptos liberales después de obtenida la independencia - en contra de los decretos de Bolívar - da cuenta no sólo de las diferencias ideológicas entre liberadores grancolombianos y criollos altoperuanos sino también de una evaluación por parte de estos últimos de las consecuencias nefastas del liberalismo político sobre la estabilidad de la sociedad estamental boliviana.

Ahí reside, a fin de cuentas, la principal diferencia del accidentado ingreso de Bolivia en la modernidad política contemporánea cuando se la compara con los países europeos e incluso con algunos de sus vecinos sudamericanos. En efecto, las revoluciones liberales implicaron el fin de los privilegios, la asunción de la soberanía (nacional primero, y popular después, materializada en una ciudadanía amplia) y una transformación de las estructuras económicas, dimensiones ausentes al término del proceso independentista del Alto Perú. El paradójico conservadurismo de los revolucionarios criollos se entiende así como una forma de preservación de su condición de estamento dominante copando además los espacios políticos y administrativos liberados por los peninsulares. Pero lo más relevante para nuestra reflexión es que la conservación de las estructuras coloniales, aunque acompañada por un republicanismo formal, no se coadunaba con el desarrollo de un proyecto nacionalista. La proclamada "conciencia de Charcas" de los primeros independentistas se asemejaba ya más a una conciencia de clase que a una conciencia nacional con pretensiones universalizantes. Si la nación es una forma de integración nacional, y si la élite criolla y mestiza rechazó la inclusión social y política del liberalismo, parece evidente que la debilidad del nacionalismo boliviano a lo largo del siglo XIX no fue un fracaso histórico sino

13 «El término 'gamonalismo’ no designa sólo una categoría social y económica: la de los latifundistas $o$ grandes proprietarios agrarios (...) Comprende una larga jerarquía de funcionarios, intermediarios, agentes, parásitos, etc. (...) El factor central del fenómeno es la hegemonía de la gran propiedad semifeudal en la política y el mecanismo del Estado», MARí́tegui, José Carlos: La realidad peruana, Buenos Aires, Tecnibook, 2010, p. 14. En el mismo ensayo (p.14), Mariátegui afirma también que «[la] liquidación del gamonalismo (...) podía haber sido realizada por la República dentro de los principios liberales y capitalistas. Pero (...) estos principios no han dirigido efectiva y plenamente nuestro proceso histórico. Saboteados por la propia clase encargada de aplicarlos, durante más de un siglo han sido impotentes para redimir al indio de una servidumbre que constituía un hecho absolutamente solidario con el de la feudalidad», cursiva nuestra. Una reflexión que se aplica perfectamente al caso boliviano.

14 Rojas Ortuste, Gonzalo: Cultura politica de las élites en Bolivia (1982-2005), La Paz, FES-CIPCA, 2009, pp. 53-54. 
que constituyó uno de los sostenes del régimen neocolonial republicano. La vertiente nacionalista del liberalismo político occidental se quedó, de este modo, atrofiada.

Por fin, también en lo que toca la relación osmótica entre afirmación del Estadonación liberal y desarrollo del capitalismo industrial, Bolivia parece ir a contramano de la Historia. La fase inicial de la Revolución Industrial en el mundo occidental coincide con las Revoluciones Liberales y encuentra guarida en el seno del Estadonación. Este, liberando la iniciativa individual, garantizando la propiedad y concluyendo una unificación espacial, fiscal y cultural del territorio estatal, crea las condiciones para la acumulación capitalista. En la sociedad rural boliviana, la creación de un mercado de tierras y la movilidad de la mano de obra pasaba, desde el punto de vista de los dirigentes criollos, por el desmantelamiento de las comunidades indígenas. A lo largo del siglo XIX, varios fueron los proyectos agrarios que buscaban este fin ${ }^{15}$ : su reiteración no hace más que ilustrar la inconsistencia de su aplicación. La resistencia indígena explica, en parte, este fracaso, como analizaremos más adelante. Pero eliminar las comunidades implicaba simultáneamente para el Estado renunciar al tributo indígena (que todavía suponía, en 1880 , un $25 \%$ del presupuesto nacional ${ }^{16}$ ) y a los servicios forzados, que subsistían desde la época colonial. Por otro lado, el tributo no podía ser reemplazado por un impuesto individual sobre la propiedad, debido a la incapacidad impositiva de las autoridades centrales ${ }^{17}$. Existía así, también en la dimensión del modelo de producción, una tensión entre intentos de modernización y factores de perduración de las estructuras tradicionales. Cuando, en el último cuarto del siglo XIX, el ritmo de los ataques a las tierras comunitarias se aceleró, su venta no favoreció la multiplicación de pequeños propietarios-ciudadanos indígenas, sino la concentración de las tierras en manos de los grandes propietarios criollos o mestizos, en el marco todavía semifeudal de la hacienda. A la vuelta del siglo, el deseo de las élites de integrar el mercado capitalista internacional a través de la construcción de una nación moderna tropezaba con su propia repugnancia a la integración de las poblaciones indígenas subalternas. A partir de ese momento, construir la nación significaba resolver el problema de "lo indio", un lastre al ideal de bolivianidad blanca, urbana y occidental, y designado como responsable del fracaso del proceso de "nacionalización" del Estado ${ }^{18}$.

Por último, hay que notar que la debilidad represiva y burocrática del Estado, la constelación de poderes locales privatizados, y las rivalidades en el seno de la dirigencia política y económica dificultaron, al menos hasta mediados del siglo XIX, la emergencia de un actor hegemónico que pudiera impulsar la construcción de una

15 DemÉlas, Marie-Danielle: La invención politica. Bolivia, Ecuador, Perú en el siglo XIX, Lima, IFEAIEP, 2003, pp. 394-416.

16 DemÉlas, op. cit. (note 2), p. 108.

17 «El gobierno desorganizado y sin fuentes de ingresos que emergió en los años 1830 y 1840 dependía de la perpetuación de las relaciones coloniales de extracción del excedente por medio del tributo, y no de la privatización o de la posesión por el Estado de las tierras colectivas indias» (HYLTON, Forrest y THOMSON, Sinclair: Horizons Révolutionnaires. Histoire et actualité politique de la Bolivie, Paris, Imho, 2010, p. 81).

18 Larson, Brooke: Trials of Nation Making. Liberalism, Race, and Ethnicity in the Andes, 1810-1910, Cambridge, CUP, 2004, pp. 247-252. 
nación autoconsciente y solidaria más allá de un Estado-nación embrionario ${ }^{19}$. Por otro lado, y como observa Tristan Platt, buena parte de la élite criolla decimonónica prefería definirse en términos étnicos más que en términos nacionales ${ }^{20}$. No hay que olvidar que los hipotéticos avances de un nacionalismo integrador - política y territorialmente - conllevarían una mayor exigencia de rendición de cuentas a un Estado en manos de una minoría y un ataque a los frágiles equilibrios entre las instituciones de un poder heterogéneo: el centralismo paceño, el gamonalismo, los empresarios mineros, o las comunidades indígenas. A lo largo del siglo XIX, las prioridades de estos actores - la defensa de su statu quo y los reajustes en los acuerdos tácitos de reparto del poder - no tenían por qué fomentar el desarrollo de un sentimiento nacional, y de hecho no lo hicieron, al menos hasta la derrota contra Chile en la Guerra del Pacífico (1879-1883) y la pérdida del acceso al mar. Existieron sin duda evoluciones en la distribución de cuotas de poder, variaciones en el grado de inclusión política de las masas e incluso proyectos de integración ciudadana, como veremos enseguida; pero hubo que esperar a un acontecimiento excepcional como la Guerra del Chaco (193235) contra Paraguay para asistir a un movimiento real hacia la cohesión nacional y un sentimiento de pertenencia a un territorio y comunidad comunes.

\section{Élites y proyectos de construcción nacional}

«No hay Estado-nación sin previa destrucción de la comunidad indígena» (José Rosendo Gutiérrez, diputado por La Paz en la Convención Nacional de 1880) ${ }^{21}$.

Las primeras décadas tras la independencia (proclamada definitivamente en 1825) estuvieron caracterizadas políticamente por una gran inestabilidad, tanto por la cantidad de liderazgos más o menos efímeros como por la proliferación de constituciones. Las diez cartas magnas entre 1826 y 1878 ilustran, por un lado, las luchas de poder en el seno de las élites (puesto que la mayor parte de los caudillos provenía de familias pudientes) y, por otro, los problemas del régimen republicano en fundar la institucionalidad estatal.

Para lo que nos interesa, el déficit de institucionalidad, al provocar el descrédito de la ley escrita - fundamento de la ciudadanía en común - e impidiendo una planificación a largo plazo, crea las condiciones para la supervivencia de otras pautas, no escritas pero más perdurables, que suponen unas reglas del juego comprensibles para todos los actores sociales, tanto dominantes como subordinados. Así, en el caso boliviano no es extraño que las estructuras fundamentales de las relaciones estamentales socioeconómicas de origen colonial se hayan mantenido durante todo el período cau-

19 Gray Molina, George: “Ethnic Politics in Bolivia: 'Harmony of Inequalities'. 1900-2000”, Crise Working Paper, 15 (febrero 2007), p. 27.

20 Platt, Tristan: "Historias unidas, memorias escindidas: las empresas mineras de los hermanos Ortíz y la construcción de las elites nacionales, Salta y Potosí, 1800-1880", Andes: Antropología e Historia, 7 (1995-1996), pp. 137-221, citado por LANGER, Erick D.: "Bringing the Economic Back In: Andean Indians and the Construction of the Nation-State in Nineteenth-Century Bolivia", Journal of Latin American Studies, 41 (2009), p. 538.

21 Citado por Demélas, op. cit. (nota 15), p. 403. 
dillista, ni que durante la mayor parte de la centuria no hubiera un cuestionamiento ideológicamente fundamentado de los roles tradicionales de las categorías sociales.

La apertura del primer gran debate desde los años 20 sobre la construcción nacional y la cuestión indígena se dio con la Convención de 1880, tras la derrota en la Guerra del Pacífico, y coincidió con el inicio de una fase de estabilidad política y de afirmación del modelo económico de la exportación minera. Detengámonos brevemente en este último punto para relacionarlo con los propósitos de construcción del Estado-nación boliviano y determinar hasta qué punto las vicisitudes de esta se vinculan con los cambios en la estructura productiva y con las resistencias a esos cambios.

Como decíamos, el último tercio del siglo XIX asistió a un incremento del volumen de la extracción minera, particularmente la plata y luego el estaño. La fuerte demanda de la industria occidental benefició no solamente a los propietarios de las minas - la oligarquía del altiplano meridional - sino también a las arcas del Estado, cuya dependencia con respecto al tributo indígena decreció progresivamente. Simultáneamente, el crecimiento de la actividad minera solicitaba mano de obra, a ser posible abundante y barata. El desmembramiento de las comunidades indígenas y la privatización de las tierras comunales respondía a estas dos tendencias, con la ventaja adicional de añadir nuevas y vastas parcelas a un mercado de tierras agotado. En pocas palabras: la integración al mercado mundial y la satisfacción de las ambiciones agrarias y mineras de los grandes propietarios se relacionan directamente con la serie de leyes de parcelación y venta de las tierras comunitarias aprobadas desde la década de 60 .

Así, la apología del Estado-nación defendida por el diputado Rosendo Gutiérrez para destruir las comunidades se aclara teniendo en cuenta que los principales beneficiados de la privatización fueron los grandes terratenientes, los propietarios de minas y la burguesía paceña, que pudieron así diversificar sus inversiones. Pero lo que podría ser considerado un simple instrumento de legitimación de la dominación no puede ser reducido simplemente a un tipo de hipocresía con motivaciones económicas: a los ojos de la clase dirigente, la identificación entre sus propios valores y expectativas de futuro y el desarrollo del Estado la llevó a valorar la desintegración de las formas comunitarias como sinónimo de consolidación de la nación, tanto hacia la modernización (tecnológica y mercantil) como hacia la modernidad (el Progreso moral). El aspecto de la participación ciudadana y de la igualdad de derechos siguió siendo oportunamente postergado, aunque para el pensamiento criollo los temas de la construcción nacional y del papel de la mayoría indígena estuviesen necesariamente conectados. La paradoja es evidente: la reclamación oligárquica del Estado-nación reflexionaba sobre la cuestión indígena pero no buscaba en ningún momento la integración, sino la continuación e incluso acentuación de la segregación social; es más, añadió a la dimensión de explotación económica, laboral y fiscal heredada de la Colonia, la dimensión biológica del racismo.

En este punto, nos parece útil profundizar en la relación entre las deficiencias del nacionalismo criollo y la exclusión del mundo indígena del cuerpo político introduciendo en la discusión el elemento racial, y más precisamente la interrelación que históricamente se comprueba entre racismo y nacionalismo, en el contexto de afir- 
mación del Estado-nación en Occidente y su irradiación mundial ${ }^{22}$. A primera vista, la República boliviana parece acomodarse a la tendencia de reciprocidad histórica entre nacionalismo y racismo, en línea con los ejemplos de los Estados Unidos segregacionistas o del antisemitismo europeo, concomitantes con la plena afirmación de las identidades nacionales. Sin embargo, el caso boliviano difiere de otros en la medida en que el racismo no se afirmó inmediatamente tras la independencia como exclusivo definidor de las relaciones sociales (al menos no más que en el periodo colonial tardío) y cuando sí se afirmó como ideología de importación, a finales de la centuria, no fue acompañado por un movimiento hacia la consolidación de la nacionalidad estatal, sino todo lo contrario: la racialización y naturalización de la posición social subordinada del indígena no tenían como objetivo la unión de la nación en torno a un enemigo común, ni mucho menos la homogeneización del mestizaje, sino afianzar y prolongar la desigualdad económica y política que afectaba a la mayoría de la población.

Por otro lado, tampoco en lo que respecta al vínculo de causalidad entre racismo y movimientos de autodeterminación se adecua Bolivia al patrón histórico. Del racismo de la metrópoli - un racismo más sociológico que institucional, atenuado por los filtros del sistema colonial dual - no resultó el nacionalismo de la autodeterminación del pueblo autóctono, como pasaría un siglo después con los colonias del mundo desarrollado. Al contrario, para los grupos criollos, el final de la crisis de independencia conllevó su paso de nacionalistas de la autoproclamada liberación a nacionalistas de la dominación ${ }^{23}$.

Así, en el caso boliviano, a la pregunta ¿quién nació primero: el racismo o la dominación?, la respuesta es clara: «El racismo, más que un sentimiento real o una herencia del periodo colonial, es la consecuencia lógica de la exclusión de esta población, una excusa para evitar la integración» de los grupos subalternos ${ }^{24}$. El racismo de finales del siglo XIX se adoptó y propagó como justificación de la dominación, en reemplazo del sistema de equilibrios corporativos en vigor hasta ese momento. Como subraya Brooke Larson ${ }^{25}$, a pesar de las diferencias ideológicas entre los miembros de los grupos dominantes criollos - fuesen ellos dirigentes políticos, potentados económicos o intelectuales - lo que los unía era el hecho de haberse autorizado a sí mismos a arbitrar y regular las fronteras de la nación, de la raza y del territorio, y de moldear los restantes sectores de la sociedad de acuerdo con su visión de futuro para el país; los cuales coincidían, evidentemente, con sus intereses de clase.

La cuestión del territorio, a la que hicimos referencia, también es un tema relevante en el nuevo paradigma nacional que ganó terreno a partir de 1880. La derrota de Bolivia en la Guerra del Pacífico y la pérdida del acceso al océano dieron origen a la manifestación traumática de un nacionalismo de la amputación. Nacionalismo territorial que también se relaciona con la naciente teoría racial, pues la responsabilidad del desastre bélico contra Chile fue parcialmente atribuida a las poblaciones indíge-

22 BALIBAR, Etienne: "Race and nationalism", en BALIBAR, Etienne y WALlERsteIn, Immanuel, Race, Nation, Class: Ambiguous Identities, Londres, Verso, 1991, pp. 37-67.

23 Ibidem, p. 46.

24 IRURozQui, op. cit. (nota 4), p. 200.

25 LARSON, op. cit. (nota 18), p. 251. 
nas. El territorio era, efectivamente, el único denominador común posible entre los habitantes de un país en que casi todo los separaba ${ }^{26}$. Había que poner fin a la dejadez del Estado con relación a sus límites: a la necesidad de prevenir futuras agresiones extranjeras se unía la voluntad de mercantilización de la tierra y de promover un cierto tipo de identidad colectiva. La definición estricta de las fronteras chocaba, como veremos en la próxima sección, con las prácticas comerciales de las comunidades y los comerciantes individuales indígenas, acostumbrados a la porosidad de las zonas rayanas. Para los hijos criollos de la independencia, la exactitud de los lindes nacionales tampoco era fácilmente imaginable, el espacio mental del Estado-nación no existía, y su identificación afectiva variaba de la "patria chica" a América como un todo. De ahí que los cambios en la política territorial de finales del siglo XIX hayan provocado vivos debates sobre el papel de las fronteras en un país en adelante mediterráneo como sería Bolivia. ¿Debería Bolivia asumirse como centro geopolítico, país de tránsito, o simple Estado tapón entre potencias regionales? ¿Había de considerar sus fronteras como barreras protectoras y garantía de la existencia del Estado o como zona de contacto, vector de integración? Aunque esta dualidad no haya sido resuelta ${ }^{27}$, podemos sugerir que la tentación de los sectores decisorios fue empezar a construir el Estado-nación desde arriba, protegiendo y sacralizando un territorio que cada vez más les iba a pertenecer, individualmente o a través del poder estatal. El ideal de la constitución de un territorio común dibujaba unos contornos afectivos a una nación fantasma.

En lo que toca al monopolio de la definición de lo que debería ser la nación y su forma de ingreso en el club de las "naciones civilizadas", las élites criollas llegaron a la conclusión consensual de que la cuestión del "retraso" indígena constituía un lastre para la modernización del país y que la principal solución para subsanar ese problema se encontraba en la educación, una vía para la "desindianización" del país. Los gobiernos liberales, vencedores de la Guerra Federal de 1899, pusieron en práctica ese proyecto de perfeccionamiento nacional con ambiciones a la altura de los significativos medios empleados. La sutileza del programa consistía, para las élites decisorias, en impulsar un proceso de modernización nacional sin poner en riesgo su propia hegemonía política, contornando la resistencia de la oligarquía terrateniente que prefería mantener a sus peones en el analfabetismo - y controlando las aspiraciones emancipatorias de los indígenas instruidos ${ }^{28}$. De él resultó una política educativa coherente y de largo alcance que, sin embargo, cambió de objetivos a medio andar. $\mathrm{Si}$ en la primera década del siglo XX uno de los principales objetivos del programa educativo pasaba por la homogeneización de los sectores subalternos mediante su integración en la cultura dominante, una segunda fase quedó marcada por el propósito de garantizar una sociedad compartimentada, con roles definidos y fijados por los

26 Perrier-Bruslé, Laetitia: "Les frontières de la Bolivie. Quelques réflexions sur l'instrumentalisation des frontières" [en línea], comunicación presentada en el coloquio internacional Vivre et tracer les frontières du monde contemporain, Tánger, 3 de febrero de 2008. laeti.perrierbrusle.free.fr/tanger2008_texte.pdf [Consulta: 1 de mayo de 2012]

27 El panamericanismo y los planes de unión con Chile y Argentina a finales del siglo XIX y comienzos del XX, son dos ejemplos de las tendencias centrífugas de la reflexión territorial boliviana.

28 Sobre este tema, nos basaremos en la reciente y detallada investigación de Martinez, Françoise: 'Régénérer la race'. Politique éducative en Bolivie (1898-1920), Paris, IHEAL, 2010. 
maestros, en que cada sector social se pusiera a su manera al servicio del desarrollo económico del país. En la práctica escolar, esto se tradujo en una escuela diferenciada a cuatro velocidades, adaptada a la extracción social y racial de los alumnos.

Según Françoise Martinez, esta segunda serie de objetivos fue cumplida de acuerdo con los criterios de los responsables liberales. La formación de indios, mestizos y mujeres fue estimulada, pero no su coparticipación social: «El nuevo orden liberal no cambió las estructuras profundas de la sociedad, y la escuela, más que como un instrumento de democratización, funcionó como un instrumento de reproducción y de consolidación de las desigualdades sociales existentes» ${ }^{29} \mathrm{Sin}$ embargo, la investigadora citada realza que este programa educativo, más allá de la instauración de una bienvenida cultura de la escuela en el conjunto del territorio, representó la primera mirada de atención de los sectores dominantes hacia grupos subalternos considerados como capaces de modernizarse. La regeneración nacional ya no podía hacerse sin su participación.

Concluyendo, y retomando una idea que ya delineamos en el apartado anterior, las insuficiencias de los proyectos nacionalistas de la República se relacionan con el rechazo en adoptar el componente indígena como elemento primordial de la nacionalidad. Creemos, de acuerdo con este planteamiento, que hay que matizar la idea extendida según la cual «tras la independencia, con el proyecto de construir en cada territorio una "nación homogénea", se pretendió eliminar la heterogeneidad o la yuxtaposición de elementos diversos (...) que caracterizaban gran parte del mundo colonial en su conjunto, con el fin de construir sociedades amalgamadas en sí mismas y autorreconocibles en un común y propio "espíritu público" de la nación» ${ }^{30}$. Si existió un proyecto, al menos hasta finales del siglo XIX, fue de consumo propio de las élites para la consolidación interna de su propia unidad y el refuerzo de su rol de fuerza moral de la nación. La incorporación del "Otro" indígena y mestizo al proyecto de desarrollo económico y moral se hizo a través de la transición de una República basada en el tributo al Estado-nación racialmente polarizado, con nuevos roles asignados a los grupos subalternos de acuerdo con parámetros bioculturales. Integrados laboralmente, por necesarios; excluidos políticamente, por peligrosos ${ }^{31}$.

En resumen: la evolución del nacionalismo de las élites decidió progresivamente eludir el problema de la ciudadanía y del cuerpo político y optó por dirigirse hacia un Estado-nación superficialmente moderno y poco o nada liberal fundado sobre la exclusión a gran escala. «El pensamiento criollo, cuando se ocupa de la diversidad de su sociedad, puede reducirse a dos grandes tendencias: ora niega esa diversidad, ora la reconoce, pero para servirse mejor de ella» ${ }^{32}$. La producción ideológica de corte racista iniciada en las dos últimas décadas del siglo XIX se inserta en esta segunda lógica. Pero, como vimos a través del ejemplo educativo, la utilización de los grupos

29 Ibidem, p. 378.

30 Marchena Olavide, Juan: "Los procesos de independencia en los países andinos: Ecuador y Bolivia", en Chust Calero, Manuel y Serrano, José Antonio (eds.): Debates sobre las independencias iberoamericanas, Madrid, Iberoamericana, 2007, p. 163.

31 LARSON, op.cit. (nota 18), pp. 14-15.

32 Demélas, op.cit. (nota 15), p. 394. 
dominados acaba por implicar el reconocimiento de su alteridad y, consecuentemente, una eventual vía de acceso a la participación en la construcción nacional.

\section{Población indígena, autonomía política y sentimiento nacional}

La historiografía reciente sobre Bolivia ha venido colmando una laguna que condicionaba la comprensión de las relaciones de las comunidades indígenas con el poder central colonial y, más tarde, el Estado republicano. Los trabajos de Silvia Rivera y su grupo de historiadores aymaras, del antropólogo Xavier Albó y, más recientemente, de Sinclair Thomson, entre otros, nos permiten analizar las dinámicas internas de las sociedades comunitarias andinas y calcular el contrapoder que encarnaban en los siglos XVIII y XIX frente al poder central, sus representantes y otros actores locales.

Thomson, en particular, abordó la "era de la insurgencia" aymara en el siglo $\mathrm{XVIII}^{33}$. Una de sus principales conclusiones es que, a lo largo de dicho siglo, las comunidades andinas lograron neutralizar el gobierno indirecto que representaba el cacicazgo y volver a arrogarse la capacidad de elegir a las autoridades comunitarias tras una serie de conflictos de poder internos en las comunidades. La crisis interna del liderazgo indígena acarreó una democratización del poder comunitario, que poco a poco cristalizó en un cuestionamiento del dominio colonial y en exigencias de autogobierno. La rebelión liderada por Tupaq Katari en 1780 y 1781 se enmarca en este movimiento que, a pesar de la derrota de la insurrección general, consiguió concebir prácticas de democracia comunal y de soberanía que se prolongarían hasta los años de la República, y constituían una alternativa a los principios políticos del liberalismo. Y más tarde, por supuesto, estas prácticas tampoco incitaban a una identificación voluntaria con el Estado recién independiente, que además ya preparaba los primeros golpes contra la propiedad comunal. Si más arriba examinamos las carencias del proyecto nacionalista criollo, hasta el punto de dudar de su existencia, cabe ahora observar más de cerca los indicios de la falta de empeño nacionalista de las poblaciones indígenas, sin menoscabo de los autores que, con razón, nos advierten sobre la diversidad interna de un mundo cuya unidad sólo existía en la mirada miope de las élites criollas.

Además de la cuestión de la autonomía política, estos indicios se basan en dos cuestiones interrelacionadas: la fiscalidad y las fronteras. Erick Langer, en un artículo reciente ${ }^{34}$, llama la atención de la necesidad de tomar en cuenta las características de la integración económica de las comunidades indígenas a la hora de analizar el grado de su incorporación sociopolítica, y sus consecuencias sobre el proceso de construcción nacional boliviano. Esta perspectiva es tanto más importante cuanto que sabemos que la atribución de la ciudadanía plena en un régimen liberal dependía de la solvencia económica del candidato a ciudadano. El autor añade complejidad regional a la teoría del "pacto recíproco" que Tristan Platt elaboró sobre las comunidades agrícolas del Norte de Potosí en el siglo XIX. Para Platt, estas comunidades aceptaban

33 Thomson, Sinclair: Cuando sólo reinasen los indios. La politica aymara en la era de la insurgencia, La Paz, Muela del Diablo-Aruwiyiri, 2007.

34 LANGER, op. cit. (nota 20). 
pagar el tributo indígena y prestar los servicios al Estado a cambio de la protección de sus tierras y un régimen aduanero proteccionista sobre los cereales ${ }^{35}$. Sin embargo, Langer defiende que este modelo no se aplica a todo el territorio de las tierras altas, puesto que una parte importante de los habitantes del altiplano (sobre todo en Oruro) se dedicaba al comercio y al transporte de minerales en un espacio transnacional, bastante próspero hasta 1860 . A estos, «sus conexiones comerciales más allá del Estado-nación les daban poco estímulo para desempeñar su papel como ciudadanos bolivianos en vez del papel de indios ${ }^{36}$. Lógicamente, apoyaban de forma pragmática un librecambismo sin barreras aduaneras mientras se valían de la debilidad estatal para practicar un contrabando floreciente; sus intereses comerciales convergían con los de los empresarios mineros mestizos y criollos con los cuales trabajaban. Como ya hemos destacado en otro lugar, ninguna de estas dos posiciones, proteccionismo y librecambismo, acercaba las poblaciones indígenas al Estado ni reforzaba su integración nacional: en el primer caso, el Estado era un socio distante; en el segundo, una autoridad fiscal indeseable ${ }^{37}$.

Sea como fuere, la relativa prosperidad económica boliviana hasta mediados del siglo XIX se debió en buena medida a los circuitos comerciales altiplánicos del espacio económico andino transnacional y a la alianza entre indígenas, algunos de ellos ricos, y del empresariado minero criollo. Langer concluye sugiriendo que el sentimiento de pertenencia nacional de los habitantes indígenas del altiplano debió variar según la actividad del individuo, su fortuna económica y su posición social, pero que el hipotético nacionalismo de los indígenas dependía sobre todo del grado de integración económica mediada por la comunidad, en detrimento de un nacionalismo de cariz político-ciudadano. Agregaríamos que este sentimiento de pertenencia económica era de cierta manera contradictorio, puesto que los intereses comerciales de ambos grupos étnicos - criollos e indios comerciantes - pasaban por el mantenimiento de un Estado débil con fronteras porosas. En pocas palabras, la integración territorial existía, pero desbordando el marco del Estado-nación.

Tanto las formas de democracia comunal como la organización del espacio y del mercado interno apuntan a una lógica paralela de los sectores no dominantes con respecto al incipiente proyecto nacional del liderazgo estatal, muy debilitado por las carencias del poder central. Y si es cierto que los ataques a las idiosincrasias comunitarias se fueron multiplicando, también lo es que una de las originalidades bolivianas consistía en la utilización, por parte de las comunidades, de los conflictos políticos entre criollos para resistir a esos mismos ataques. Aunque su rol de árbitros no siempre obtenía la recompensa esperada, las alianzas con tal o cual sector de las élites criollas constituían un recurso para interferir en la política estatal al más alto nivel.

35 Platt, Tristan: Estado boliviano y ayllu andino: tierra y tributo en el Norte de Potosí, Lima, Instituto de Estudios Peruanos, 1982.

36 LANGER, op. cit. (nota 20), p. 533.

37 Gomes, David: "Le peuple elliptique: nouveau sujet politique et indigénéité d'État dans la Bolivie contemporaine", comunicación presentada en la Jornada de Estudios Doctorales De la question sociale à la question politique en Amérique Latine, Paris, École des Hautes Études en Sciences Sociales (EHESS), 23 y 24 de mayo de 2011. 
Un ejemplo de esto es la caída del caudillo Melgarejo, en 1871, tras su iniciativa de abolir las propiedades comunitarias indígenas: la reversión de esta decisión se debió a una relación de fuerzas impuesta por las comunidades, guiadas por un aguzado sentido político, alternando formación de alianzas, amenazas de revueltas y acciones contra los gamonales o los representantes del Estado. Después de la aprobación de las leyes agrarias de 1880, a pesar de la progresiva erosión de las propiedades comunales y de la estructura interna de las sociedades indígenas, la resistencia por vía jurídica o violenta continuó. También aquí las reminiscencias del pacto tácito de autonomía entre indios y Corona resurgieron: «Jamás se han mostrado tantos títulos coloniales como a fines del siglo XIX, cuando las comunidades exigen el respeto de las garantías que el Antiguo Régimen les había ofrecido» ${ }^{38}$. Asimismo, el apego de las comunidades al pago del tributo ${ }^{39}$ durante todo el siglo es una aparente contradicción que se explica por la misma preocupación: conservar su régimen de tierras fuera del alcance de las haciendas o de los propietarios individuales, aunque fuera a cambio de una carga fiscal significativa. El movimiento de resistencia prosiguió hasta triunfar provisionalmente con la victoria de sus aliados liberales criollos en la Guerra Federal de 1899, otro ejemplo más de los contactos permanentes entre las sociedades criollas e indígenas y de la importancia de la negociación entre ambas partes. A pesar de sus esfuerzos, se estima que en las dos últimas décadas del siglo XX las comunidades acabaron siendo despojadas de un tercio de sus tierras ${ }^{40}$.

Con estos elementos en mano, y atentos al peligro del anacronismo conceptual, ¿será posible emitir un juicio sobre el grado de identificación de los pueblos indígenas con el proyecto nacionalista criollo? El caso de las comunidades bolivianas y peruanas que se instalan a uno y otro lado de la frontera conforme a las variaciones de la carga fiscal, son un buen ejemplo de la ausencia de lazos afectivos a un país aún joven y sin antecedentes, salvo la delimitación administrativa del Alto Perú. También es cierto que, a lo largo del siglo XIX, «las creencias republicanas y los símbolos patrióticos se difundieron de modo reducido. La historia nacional no servía para consolidar una solidaridad e identidad republicanas $)^{41}$. La vía de la instrucción tampoco fue privilegiada, y cuando sí lo fue, su alcance quedó voluntariamente limitado. La integración ciudadana, por su parte, principal cimiento de la nacionalidad, fue descartada una y otra vez por hacer peligrar los intereses de los mismos nacionalistas. En este contexto, tal vez tengamos que plantear la posibilidad de que el reconocimiento de la presencia del Estado y de la pertenencia a un territorio común haya llegado, además de por el factor económico, por los episodios de negociación entre comunidades y Estado. Podemos suponer que esta casi constante serie de "tira y afloja", de chantajes, alianzas y revueltas, haya acabado por formar en el espíritu tanto de los dominados como de los dominantes un marco común de discusión. El tono "republicano" del discurso del general aymara Zarate Willka en la Guerra Federal de 1899 es una señal, y no la única, de ese lenguaje compartido.

38 DemÉlas, op. cit. (nota 15), p. 406.

39 Platt, op. cit. (nota 20), pp. 12-15.

40 IrurozQui, Marta: Elites en litigio. La venta de tierras de comunidad en Bolivia, Lima, Instituto de Estudios Peruanos, 1993, citado por Hylton y Thomson, op. cit. (nota 17), p. 86.

41 Demélas, op.cit. (nota 15), p. 517. 
Las formas de esa negociación y el lenguaje común también influyeron en los tipos de reivindicaciones dirigidas al Estado, y viceversa. La resistencia, multiforme, intentó proteger lo que quedaba de la propiedad comunal con una estrategia a largo plazo adaptada a las circunstancias políticas, pero prefiriendo siempre que fue posible imponer el regreso al pacto de no-agresión entre comunidades y Estado a una transformación radical de la sociedad ${ }^{42}$. Creemos que hay elementos suficientes para afirmar que la justificación simbólica de las revueltas locales o insurrecciones regionales basada en el utopismo incaico o en la guerra de exterminación, cuando se produjo, no implicó una adhesión generalizada por parte de las poblaciones indígenas. Los últimos veinte años del siglo XIX, el período de mayor ataque a las tierras comunitarias, no vieron surgir ningún movimiento milenarista ${ }^{43}$. Al mismo tiempo, una parte de los miembros de las comunidades logró ingresar en el sistema de posesión individual de tierras, convirtiéndose en pequeños propietarios de identidad ambivalente, a medio camino entre el comunalismo y el liberalismo. Sin embargo, como vimos en el apartado anterior, a la vuelta del siglo los titulares del Estado estaban sobre todo empeñados en eliminar los vestigios de ese pacto.

En esta línea, compartimos la posición de Pilar Mendieta, cuando contraría el mito de la resistencia permanente de las comunidades indígenas y prefiere destacar su creciente participación en la vida política y la importancia de la correlación evolutiva de fuerzas con el Estado y los demás actores ${ }^{44}$. En el siglo XIX, las relaciones clientelares de protección con el Estado y los poderes locales para preservar el estatuto comunitario fueron una constante. Las revueltas advinieron cuando los cambios fueron demasiado profundos y los mecanismos de negociación no funcionaron: el primer gran ciclo de insurrecciones indígenas, a mediados del siglo XVIII, ya se había debido en buena medida a la injerencia que las reformas borbónicas suponían para la autonomía del mundo comunitario. De todos modos, sería anacrónico ver en el momento álgido de ese ciclo, la Gran Rebelión de 1780-81, el nacimiento de una aspiración "nacional" indígena, como lo hacen algunos autores, o incluso el punto de arranque de una "memoria larga" de indigenismo anticolonialista que alimenta las luchas del pasado cercano y del presente ${ }^{45}$. A nuestro modo ver, la perspectiva que ve a los pueblos indígenas bolivianos agazapados en la Historia, esperando el momento adecuado para subvertir la dominación blanca y occidental, parte de un presupuesto ideológicamente marcado e incluso ahistórico, al subestimar otras formas de relaciones de poder no violentas y los cambios estructurales de largo plazo que imposibilitan

\footnotetext{
42 A pesar de que, en casos extremos, surgieron discursos radicales de liberación étnica. Véase PLATT, Tristan: "Liberalism and Ethnocide in the Southern Andes", History Workshop Journal, 17 (1984), p.15 y THOMSON, op.cit. (nota 33), pp. 274-276.

43 Demélas, op.cit. (nota 2), p. 163.

44 Mendieta Parada, Pilar: "Política y participación indígena en Bolivia: una reflexión desde la Historia: siglos XIX-XXI", en GreBe LóPEZ, Horst (coord.): Continuidad y cambio en el orden político. Las transiciones en el contexto constituyente, La Paz, Prisma, 2008, pp. 11-32.

45 Para el primer caso, véase DELFOUR, Christine: L'invention nationaliste en Bolivie. Une culture politique complexe, Paris, L'Harmattan, 2005, p.107; para el segundo, ALBÓ, Xavier: "Larga memoria de lo étnico en Bolivia, con temporales oscilaciones", en CRABTREE, J. y otros, Tensiones irresueltas: Bolivia, pasado y presente, La Paz, Plural Editores, 2009, pp.19-40 o RIVERA, Silvia: 'Oprimidos pero no vencidos'. Luchas del campesinado aymara y qhechwa 1900-1980 (4a edición, edición original: 1984), La Paz, La Mirada Salvaje, 2010
} 
comparaciones apresuradas. La emergencia historiográfica en las últimas décadas de los grupos subalternos vino añadir complejidad a una visión limitada que privilegiaba tradicionalmente la historia política de los sectores criollos. Pero destacar la acción indígena no significa, ni olvidar su diversidad interna o la intersección con otras formas de identidad, ni atribuirle una dirección resolutamente revolucionaria. Iniciativa indígena hubo, sin duda, pero adaptada a los ritmos históricos, acompañando sus dinámicas internas y valorando sus relaciones con los demás actores, incluyendo las tensiones, negociaciones, acuerdos, cesiones y alianzas con los grupos dominantes.

\section{Nación, Estado, ¿convivencia democrática?}

En las páginas anteriores, pretendimos demostrar que, en las sucintas palabras de Marta Irurozqui, «el proyecto de Estado nacional boliviano fue (...) el de una clase que aspiraba a su propio engrandecimiento y que lo llamaba nacional porque no concebía ni se planteaba que otros tuviesen derecho a ello» ${ }^{46}$. Sugerimos, en primer lugar, que el nacionalismo criollo debió su debilidad inicial a la conservación de las estructuras de equilibrio colonial que no se ajustaban al modelo del Estado-nación burgués. Sin embargo, cuando la posibilidad de romper con ese sistema basado en el tributo indígena se presentó, en el último tercio del siglo XIX, el camino elegido por las élites tendió hacia la acentuación de la exclusión ciudadana de la mayoría indígena y el respectivo abandono del precepto liberal de igualdad individual. Desde el punto de vista indígena, resaltamos la importancia de dos factores, el económico-comercial y el de la negociación, en la conformación de las relaciones de las comunidades y los comerciantes indígenas con el Estado. Propusimos una visión de la agencia subalterna más basada en los cambios internos y en la continuidad de la negociación que en la excepcionalidad de la insurrección.

A manera de conclusión, quisiéramos formular un comentario sobre las consecuencias hasta la actualidad del establecimiento en Bolivia de un Estado-nación truncado. Primeramente, debemos subrayar - como hemos venido argumentando - que en el binomio "Estado-nación" boliviano los componentes han sido enemigos históricos. Fue el Estado, en manos de una clase dirigente, el que puso en práctica políticas que no sólo construían una nación restringida (como la reforma educativa de comienzos del siglo XX), sino que en muchos casos rechazaban a la mayoría de la población como siquiera pretendiente a incorporarse a la nación autoproclamada. Esa dicotomía continuó todo el siglo pasado, en particular a través del racismo institucionalizado.

En segundo lugar, a menos que tengamos pretensiones moralistas, no parece tener mucho sentido culpar a las élites por el fracaso de algo que esta ni siquiera intentó. La gran capacidad de regeneración de la clase dominante, con cambios periódicos del sector preponderante en su seno, está en la base de su comportamiento a-nacional. Culpar a los criollos bolivianos sería como dar las gracias a la burguesía francesa o americana por haber construido una ficción compartida que, aunque duradera, favoreció sobre todo a quienes la crearon.

46 IRUROZQUI, op.cit. (nota 4), p.17 
Tertio, si Renan preguntaba “¿Qué es una nación?”, no deberíamos nosotros interrogarnos sobre ¿Para qué la nación? ¿Es la nación un objetivo? ¿Van, o deben ir, todos los Estados hacia la inevitable construcción nacional tal como la conocemos? Desde la Revolución de 1952, el nacionalismo boliviano ha estado marcado por temas potencialmente conflictivos, como la demanda de mar con soberanía y la denuncia del enemigo interno y externo. Si consideramos que la indianidad es un factor esencial de la identidad boliviana, que tiene que ser integrado a la construcción institucional y afectiva del Estado, ¿es la fórmula del Estado-nación la más adecuada para llevar a cabo ese proceso?

Creemos, para finalizar con algunas respuestas, que la experiencia actual del Estado plurinacional boliviano, con su modelo descentralizado de autonomías indígenas, podrá significar una alternativa al modelo uniforme de nación "una e indivisible" que deriva frecuente y peligrosamente hacia el esencialismo identitario o al separatismo de nacionalismos periféricos. Un posnacionalismo intercultural como el que se proyecta en Bolivia puede servir como identidad refugio, albergando en su territorio simultáneamente varias identidades subestatales en igualdad de condiciones. Además, en el caso boliviano, el posible posnacionalismo no proviene de una disolución del Estado-nación en el mundo económica y culturalmente globalizado; ni de una integración regional fuente de transferencias de soberanía y de una hipotética identidad supranacional, como en el caso europeo; ni mucho menos de una tendencia hacia una relación estrictamente contractual y política entre ciudadanos y Estado en el marco de la democracia representativa; sino de un acuerdo consciente entre los varios elementos que componen la diversidad cultural. Y, en ese sentido, el déficit de nacionalismo jacobino y agresivo, y el fracaso de la nación boliviana decimonónica, dejarían de constituir una carencia, pasando a ser una virtud. 